\title{
Investigating The Effects of Audio Exposure toward Podcast Listener Loyalty via Theory of Planned Behavior (A Study on Urban Millennials in Jakarta)
}

\author{
JERRY S. JUSTIANTO ${ }^{1}$, MTS ARIEF², INDAH SUSILOWATI², MUHAMAD ARAS ${ }^{2}$ \\ ${ }^{1}$ Doctor of Research in Management Binus Business School, Binus University Jakarta Indonesia \\ J1. K. H. Syahdan No. 9, Kemanggisan, Palmerah,Jakarta, 11480, \\ INDONESIA \\ ${ }^{2}$ Management Department, BINUS Business School Doctor of Research in Management, \\ Bina Nusantara University, Jl. K. H. Syahdan No. 9, Kemanggisan, Palmerah,Jakarta, 11480, \\ INDONESIA
}

\begin{abstract}
The purpose of this study was to determine the effect of audio exposure on podcast listener loyalty through the theory of planned behavior. This research method uses quantitative research methods using SEMPls. The results showed that there was an indirect effect on the frequency of AOD exposure that was positively related to individual attitudes towards AOD loyalty. While the frequency of AOD exposure is positively related to accepted subjective norms, there is no indirect effect of AOD exposure frequency related to subjective norms on AOD loyalty. While the frequency of AOD exposure has a positive but not significant effect on individual AOD loyalty, there is no indirect effect on the frequency of AOD exposure that is positively related to the individual's perceived behavioral control on AOD loyalty. Meanwhile, AOD has a positive and significant effect on AODLoyalty. Perceived subjective norm has a positive and significant effect on AOD loyalty attitudes. Perceived subjective norms have a positive but not significant effect on individual AOD loyalty. Perceived subjective norm has a positive and significant effect on AOD loyalty perceived control. From these results obtained a hypothesis which states that Perceived behavior control related to AOD is positively related to AOD loyalty attitudes and Perceived Behavior Control over AOD is positively related to AOD Loyalty. Perceived Behavior Control has a positive and significant effect on AOD Loyalty.
\end{abstract}

Key-Words:- Podcast Perceived Behavior Control, loyalty perceived control, Perceived subjective norm, subjective norm

Received: June 8, 2021. Revised: January 22, 2022. Accepted: February 10, 2022. Published: February 25, 2022.

\section{Introduction}

The phenomenon of podcasting, dating its origins to 2004, can be understood as a partial fulfillment of that prophecy. While the Internet has not yet killed the radio station, both Internet radio and podcasting specifically have continued to grow in popularity, each with monthly audiences of over 35 million people [1]. Podcasts have several advantages over traditional radio, in that they generally have little to no advertising, allow audiences to time-shift their listening, and allow for a more personalized listening experience. Podcasting can therefore be seen as both a boon and a challenge to traditional broadcasting[1].
With the rise of the trend of Audio on Demand, the radio industry has to move to this new platform. As the industry is known for identic to audio media, now the content has been shifting to another format: radio streaming and podcast. Some experts believe that Podcasting as Radio's Revival [2]. Podcasting is a technology that allows users to download, store, and play back both audio and audio-visual content files [3]. In facts, not only radio industry is the one who instinctively shall be adapt to these two platforms, but other media is also looking to audio content, including 
TV stations, Magazines, Newspaper, all are having great podcast channel lineup.

One of the reasons of the increasing demand for audio-media is due to the multi-tasking generation which busy with their smartphone running several tasks at the same time was shown by Federica Furlan that "when media are experienced simultaneously, the foreground medium dominates over the background in the audience's attention." The results of the study conclude that persons engaging in multi-tasking in device have lower attention levels than non-media multi-taskers [4].

If Podcasting is the main format that many industries cherish and recommend for content creator from conventional media and new media to look for, we have to see several reasons, why they choose Podcasting as the main source for their audio-content distribution[5,6]. Unlike radio broadcasting that need license, and internet radio that need 24 hours programming and streaming cost, Podcast is a convenient way of storing and distributing the audio content. Dario Llineres stating in his book Podcast the parameters of the new aural culture as "The processes of production and the creation of content affords new freedoms with regard to the communication of knowledge[7]. The medium's hybridity of thought, sound and text perhaps even fosters a reinvigoration of the dialectic, an exchange of ideas beyond what is possible in purely written form - be it in a magazine or academic journal[8]. Podcasting, for us, taps into something fundamental about oral communication, argument and even the tension between subjective and objective knowledge that has been amplified in the digital age [9].

The fact that the media industry reacts to the opportunistic premise of Podcasts as the dominant format of audio on demand, while the quantity or time spent listening among all audio exposures tracked by Edison Research, Podcasts comprise only $4 \%$ for the general audience, and $28 \%$ for users heavy podcasts [26]. Given the demand for Audio on Demand increased significantly by $58.7 \%$, we will see the inability of Podcasts to capture the time spent listening to the audience [27]. These issues will raise several research questions to answer what the industry is facing, one of which, for example is why the media industry puts so much effort into creating content via podcasts as the preferred audio on demand channel while acknowledging only a small amount of effort. "Share of Ear" which is only 4\%. Another question might be through what channels or tools in particular the industry should focus on, so that more userfriendly content for millennials' multitasking behavior can be found more easily and hook them up to increase time spent listening.

This research which hopefully finding the role of active and passive type of content which will be researched using the introduction of Content Density using Quantitative Content Analysis incorporating MMI switch ability to see the effect on multitasking environment that can lead to the increasing number of users and time spend of listening.

\section{Literature Review}

\subsection{Theory of Planned Behavior}

According to the theory of planned behavior (TPB) [10], behavioral intention, or the precondition of behavior, is predicted by three factors: behavioral attitude (the degree to which one is in favor of or opposed to performing a behavior), perceived behavioral control (an individual's perceived ability to perform a behavior), and subjective norms (an individual's perception of the degree to which important others think whether he or she should perform a behavior). Additional research reported that the three independent variables: applied attitude, subjective norms, and perceived behavioral control to predict ICT adoption intention found that all three variables were significant predictors of college students' intention for utilizing an online learning system[11]. Several studies also consistently using TPB combine with or without implementing subjective norm perceived norms such as:

Factors of Online Learning Adoption: A Comparative Juxtaposition of the Theory of Planned Behavior and the Technology Acceptance Model; The results show that both TAM and TPB predict elearning adoption intention well [12].

\subsection{Hypotheses Development}

Tai-Kuei $\mathrm{Yu}$ in "An empirical study combining the task technology fit model with the theory of planned behavior" offers a new perspective on the task technology fit model (TTF) into TPB model construct via the attitude variable along with the other TPB variables[3,13]. Mou in predicting the podcast intention, also refer to non-technological factors that give stronger predictor via the perceived behavior control from Xigen Li study on technology attributes toward perceived value of information $[3,14]$. 
Following are Hypotheses for structural equation models for the research model. The empirical study of Lin and Mou, the journal that studied the podcast adoption based from the theory of planned behavior, the subjective norm in the model, Lin split it into descriptive norm and injunctive norm for the purpose finding which one have more effects [3]. However, since the independent variable is exposure frequency, instead of communication frequency, the use of original TPB is preferred to the separation of subjective norms like in Mou 2015. The constructs of perceptions, subjective norms, as well as perceived behavior control are believed to be educated by underlying beliefs. The TPB has been used by many scientists to anticipate a number of behaviors [15]. And these lead to following hypotheses:

Audio Exposure or Exposure Frequency is the method of looking and what is the most audio media that reach the audiences ear, and how the effect of toward listener loyalty, attitude, subjective norms, and perceived control. This correspond to the study of Havlena [16] in synergistic effects of cross-platform media channels exposure toward awareness of message[16].

H1 : AOD exposure frequency is positively related to individual attitude toward AOD loyalty

H2 : AOD exposure frequency is positively related to subjective norm toward AOD loyalty

H3 : AOD exposure frequency will positively related to individual's AOD Loyalty

H4 : AOD exposure frequency is positively related to individual perceived behavior control toward AOD loyalty

For Attitude connecting to the exposure frequency then to loyalty is a modification from Mou from communication frequency to intention [3].

H5 : Attitude toward AOD is positively related to AOD-Loyalty

Subjective norm has been discussed a lot as determinant factor for intention and behavior, the approach for the model is using social norm for the dimension indicator to be measured. Unlike Mou original research model which dividing the subjective norm into descriptive and injunctive norm, this will return it back to its original format $[3,10]$

H6 : Perceived subjective norm associated toward AOD is positively related to AOD loyalty attitude

H7 : Perceived subjective norm associated with AOD use is positively related to individual's AOD loyalty
H8 : Perceived subjective norm associated toward AOD is positively related to AOD loyalty perceived control

Perceived Behavior in this case is about the comfortableness of users toward tools adoption, which mostly in this case is Apps. With current apps, nowadays, not only giving accessibility or user interface that is easy to use, moreover with the advancement of deep learning algorithm, but the data mining of user's preference had also been recorded and monitor closely. Recommendation algorithms are several of the most powerful machine learning systems today due to their capability to shape the info we consume. For example, YouTube's algorithm, especially, has an outsize impact. The platform is believed to be second only to Google in net visitors, and $70 \%$ of what customers watch is given to them through suggestions. In recent years, this impact has come under serious scrutiny. Because the algorithm is enhanced for getting folks to participate with movies, it is likely to provide decisions that reinforce what someone probably wants or perhaps believes, which could produce an addictive experience which shuts out some other non-relevant contents [16].

H9 : Perceived behavior control associated toward AOD is positively related to AOD loyalty attitude H10 : Perceived Behavior Control over AOD is positively related to AOD Loyalty

\section{Methods}

The main model is SEM on 5 variables: Exposure Frequency, Subjective Norms, Attitude, Perceived Control, and Loyalty. Modified version of Mou and Lin [3] research on Podcast, especially on the variable Attitude toward podcast use. The approach that I will use is looking at Edison Research way in constructing the antecedent variable toward the "share of ear" rating, which are: source, content type, location, and device. In this case, the source is the first thing that people use to get the AOD, which are the channel of the contents pass through the audience. They are: 


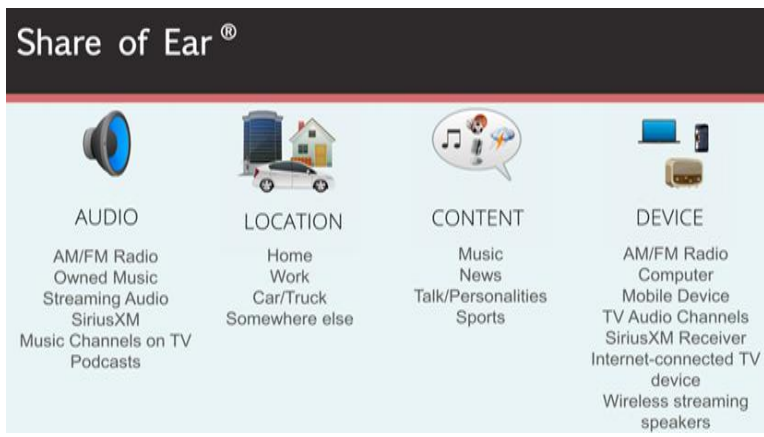

Fig. 1: Share of Ear Sources [18]

As a result, the dimension for Attitude will be the audio source comes first, and in Indonesia the sources are Radio, Owned Music, Streaming Service, TV, and Podcast. These are the sources, which can be accessed via any devices.

\subsection{Profile Respondent}

In reversal of Mou [3] research in using purposive sampling of people who have not used podcast, this survey is selecting millennials for young adults such as university students; that have grown up with smartphones and have experienced in consuming audio on demand and that include audience that solely using video on demand, such as YouTube, for the reason that most people consume the audio section more than the video itself when busy doing multitasking [25].

Among the 339 responders via a web and mobile based survey using SurveyHero.com, the completed answered is by 236 responders which of those are audio on demand users, $95.8 \%$ are using some kind of apps or tools to access the content for example: Spotify are $88.6 \%$, Joox $23.7 \%$, and Apple Music is only $16.1 \%$, and $90.3 \%$ of the completed surveys are also consuming video streaming service. The final number of responders that are used for statistic calculation are 206 responders for both the switchability testing of content density and SEM. With median age of 25.2, Male and Female consist of $41.7 \%$ and $58.3 \%$. Students are consisting of $40.3 \%$ and employees are $46.6 \%$. And the responders also stating that they aware of the audio exposures that they encounter, with average of 4.8 hours. And the average minutes of consuming Podcast or Video Cast in average of 45 minutes per day or approximately $15.6 \%$ using the "share of ear" method [18], comparing to the data for purposive podcast users in United States, the share of ear is $28 \%$ (vs $4 \%$ for all audience), and millennials AOD users based on Westwood One study spending 6.4 hours per week consuming audio podcast or translate to 55 minutes a day [18]. This prove the wave of listening audio on demand is correspond to Jakarta urban millennials.

Table 1. Table Respondents

\begin{tabular}{|c|c|c|c|c|}
\hline Age & 25.2 & & & \\
\hline Male & 86 & $41.7 \%$ & & \\
\hline Female & 120 & $58.3 \%$ & & \\
\hline Students & 83 & $40.3 \%$ & & \\
\hline Workers & 96 & $46.6 \%$ & & \\
\hline \multicolumn{3}{|c|}{$\begin{array}{l}\text { Average of Audio Exposure per } \\
\text { day }\end{array}$} & 4.8 & Hours \\
\hline & & & 288 & Minutes \\
\hline $\begin{array}{l}\text { Average } \\
\text { Listening }\end{array}$ & Podcast & & 45 & Minutes \\
\hline
\end{tabular}

Another interesting fact is the tools adoption (include application or website) used to explore the audio on demand among millennials, based on Westwood One comparing to this research are as follow [19]:

Table 2. Table tools adoption

\begin{tabular}{|l|l|l|}
\hline Name of Tools & This Study & US Millennials \\
\hline Spotify & $89 \%$ & $43 \%$ \\
\hline YouTube & $44 \%$ & $40 \%$ \\
\hline Joox & $24 \%$ & - \\
\hline Apple Podcast & $16 \%$ & $37 \%$ \\
\hline
\end{tabular}

Source: processed data (2021)

\section{Analysis and Discussion}

\subsection{Goodness of Fit Model}

In testing the suitability of the model (Goodness of Fit - Model), there are 3 types of tests including the suitability test of the measurement model (outer model), structural model fit test (inner model) and Evaluation of Goodness of Fit (GoF) - Inner Model.

\subsection{Outer Model}

For testing the outer model by looking at the results of convergent validity and discriminant validity. Convergent validity is measured by loading factor and Average Variance Extracted (AVE) parameters; Construct Reliability is measured by Cronbach's Alpha and Composite Reliability parameters. An 
indicator is declared valid if it has a loading factor above 0.70 for the intended construct while the Average Variance Extracted (AVE) value generated by all constructs must be above $>0.5$. And to see the results of construct reliability, the Cronbach's Alpha and Composite Reliability values must be above 0.7 [20].

Table 3. Reliability and Validity Test Results

\begin{tabular}{|c|c|c|c|}
\hline $\begin{array}{l}\text { Research } \\
\text { constructs and } \\
\text { research items }\end{array}$ & $\begin{array}{l}\text { Loading } \\
\text { factor } \\
>0.5\end{array}$ & $\begin{array}{l}\text { Composite } \\
\text { reliability > } \\
0.7\end{array}$ & $\begin{array}{l}\text { Ave. var. } \\
\text { extracted } \\
>0.5\end{array}$ \\
\hline $\begin{array}{l}\text { Exposure } \\
\text { Frequency }\end{array}$ & & \multirow[t]{6}{*}{0.875} & \multirow[t]{6}{*}{0.585} \\
\hline - EF101 & 0.715 & & \\
\hline - EF102 & 0.828 & & \\
\hline - EF103 & 0.770 & & \\
\hline - EF104 & 0.794 & & \\
\hline - EF105 & 0.710 & & \\
\hline Usefulness & & \multirow[t]{4}{*}{0.807} & \multirow[t]{4}{*}{0.926} \\
\hline - AT101 & 0.918 & & \\
\hline - AT102 & 0.917 & & \\
\hline - AT103 & 0.859 & & \\
\hline Genre & & \multirow[t]{5}{*}{0.571} & \multirow[t]{5}{*}{0.842} \\
\hline - AT111 & 0.731 & & \\
\hline - AT112 & 0.797 & & \\
\hline - AT113 & 0.756 & & \\
\hline - AT114 & 0.738 & & \\
\hline Ease of Use & & \multirow[t]{6}{*}{0.634} & \multirow[t]{6}{*}{0.896} \\
\hline - PC101 & 0.766 & & \\
\hline - $\mathrm{PC} 102$ & 0.866 & & \\
\hline - $\mathrm{PC} 103$ & 0.847 & & \\
\hline - PC1041 & 0.768 & & \\
\hline - PC1042 & 0.726 & & \\
\hline Auto Suggestions & & \multirow[t]{4}{*}{0.668} & \multirow[t]{4}{*}{0.857} \\
\hline - PC201 & 0.875 & & \\
\hline - $\mathrm{PC} 202$ & 0.863 & & \\
\hline - $\mathrm{PC} 203$ & 0.703 & & \\
\hline Social Norm & & \multirow[t]{6}{*}{0.650} & \multirow[t]{6}{*}{0.902} \\
\hline - SN01 & 0.713 & & \\
\hline - $\mathrm{SN} 02$ & 0.823 & & \\
\hline - SN03 & 0.762 & & \\
\hline - SN04 & 0.836 & & \\
\hline - SN05 & 0.885 & & \\
\hline Continuance & & \multirow[t]{5}{*}{0.801} & \multirow[t]{5}{*}{0.941} \\
\hline - LL101 & 0.920 & & \\
\hline - LL102 & 0.946 & & \\
\hline - LL103 & 0.906 & & \\
\hline - LL104 & 0.802 & & \\
\hline Advocating & & \multirow[t]{4}{*}{0.597} & \multirow[t]{4}{*}{0.816} \\
\hline • LL201 & 0.764 & & \\
\hline - LL202 & 0.794 & & \\
\hline - LL203 & 0.759 & & \\
\hline
\end{tabular}

Source: processed data (2021)

Furthermore, discriminant validity is used to test the validity of a model, measured by the cross-loading value parameter which contains the magnitude of the correlation between constructs and their indicators and indicators from other constructs. The cut off value used for cross loading must be greater than 0.70 . The discriminate validity test using the AVE value is carried out by comparing the root value of the AVE of each construct with the correlation between the constructs and other constructs. It is recommended that the AVE value should be greater than 0.50 [21]. Table 3 shows that the root value of the AVE of each construct is greater with the correlation between constructs and other constructs. So it can be concluded that it has good discriminant validity.

\subsection{Inner Model}

Assessing the inner model is to see the relationship between latent constructs by looking at the estimation results of the path parameter coefficients and their level of significance. In the assessment of the inner model by looking at the R-square for each dependent latent variable[22]. The following is the R-square value in the construct:

Table 4. R-Square

\begin{tabular}{|l|l|}
\hline Dependent variable & R Square \\
\hline Attitude & 0.364 \\
\hline Listener Loyalty & 0.384 \\
\hline Perceived Control & 0.068 \\
\hline Subjective Norm & 0.048 \\
\hline
\end{tabular}

Source: processed data (2021)

In the table $* * * 4.13$ the $\mathrm{R}$-Square value for the Attitude construct gives a result of 0.364 . This means that the Attitude construct can be explained by the Exposure Frequency, Subjective Norm and Perceived Control constructs of $36.4 \%$.

The R-Square value of Listener Loyalty construct is 0.384 . This means that the construct of Listener Loyalty is explained by the constructs of Attitude, Subjective Norm, Exposure Frequency and Perceived Control of $38.4 \%$.

The R-Square value of the Perceived Control construct is 0.068 . This means that the construct of Perceived Control is explained by Subjective Norm and Exposure Frequency of $6.8 \%$. And finally, the RSquare value of the Subjective Norm construct is 0.048 . This means that the Subjective Norm construct is explained by the Exposure Frequency construct of $4.8 \%$.

\subsection{GOF Evaluation of Inner Model}


To evaluate the GoF - Inner Model, it is done by looking at the values of R-Square $\left(\mathrm{R}^{2}\right), \mathrm{Q}$-Square $\left(\mathrm{Q}^{2}\right)$ and GoF. Following is the test of Inner Model with $\mathrm{Q}^{2}$ (predictive relevance):

$$
\begin{aligned}
& \mathrm{Q}^{2}=1-\left(1-\mathrm{R} 1^{2}\right)\left(1-\mathrm{R} 2^{2}\right)\left(1-\mathrm{R} 3^{2}\right)\left(1-\mathrm{R} 4^{2}\right) \\
& \mathrm{Q}^{2}=1-(1-0.364)(1-0.384)(1-0.068)(1- \\
& 0.048) \\
& \mathrm{Q}^{2}=1-0.348 \\
& \mathrm{Q}^{2}=0,652
\end{aligned}
$$

From these results in $\mathrm{Q}^{2}(0.652)>0$, it shows that the model has predictive relevance [22]. The $\mathrm{Q}^{2}$ predictive relevance value of 0.652 indicates that the model is strong.

Next, look for the Goodness of Fit (GoF), which is calculated by the square root of the average communality index value with the R-Square $\left(\mathrm{R}^{2}\right)$ average.

\section{$\mathrm{GoF}=\sqrt{\operatorname{Com} x R^{2}}$}

The Com value is obtained from the average AVE value of 0.72 so that the GoF value can be calculated as follows:

$$
\begin{aligned}
& \mathrm{GoF}=\sqrt{0,701 \times 0,652} \\
& \mathrm{GoF}=\sqrt{0,321} \\
& \mathrm{GoF}=0,566
\end{aligned}
$$

The GoF value of 0.566 indicates that the model in this study is included in the Strong criteria.

\subsection{Hypotheses Testing and Discussions}

To test the hypothesis using the output path coefficients (Mean, STDEV, T-Values) provided that if the $t$ statistic value obtained from the table is greater than 1.96 and the p-value <0.05, the hypothesis between the existing variables is accepted. On the other hand, if the value of t statistics is less than 1.96, the p-value $>0.05$, then the hypothesis is rejected. There are two submodels in a structural equation model; the inner model specifies the relationships between the independent and dependent latent variables, whereas the outer model specifies the relationships between the latent variables and their

\begin{tabular}{|c|c|c|c|c|c|}
\hline & & $\begin{array}{l}\text { Original } \\
\text { Sample } \\
(\mathrm{O})\end{array}$ & $\begin{array}{l}\mathrm{T} \\
\text { Statistic } \\
\mathrm{s} \\
(\mid \mathrm{O} / \mathrm{STE} \\
\mathrm{RR} \mid)\end{array}$ & P-Value & Result \\
\hline \multicolumn{6}{|l|}{ Direct Effect } \\
\hline $\begin{array}{l}\text { Exposure } \\
\text { Frequency } \\
\text { Attitude }\end{array}$ & $->$ & 0.124 & 2.037 & 0.042 & $\begin{array}{l}\text { Significant } \\
\mathrm{H} 4\end{array}$ \\
\hline $\begin{array}{l}\text { Exposure } \\
\text { Frequency } \\
\text { Subjective } \\
\text { Norm }\end{array}$ & $->$ & 0.220 & 3.537 & 0.000 & $\begin{array}{l}\text { Significant } \\
\text { H5 }\end{array}$ \\
\hline $\begin{array}{l}\text { Exposure } \\
\text { Frequency } \\
\text { Listener } \\
\text { Loyalty }\end{array}$ & $\rightarrow$ & 0.019 & 0.293 & 0.769 & $\begin{array}{l}\text { Not } \\
\text { significant } \\
\text { H6 }\end{array}$ \\
\hline $\begin{array}{l}\text { Exposure } \\
\text { Frequency } \\
\text { Perceived } \\
\text { Control }\end{array}$ & $\rightarrow$ & 0.109 & 1.576 & 0.115 & $\begin{array}{l}\text { Not } \\
\text { significant } \\
\text { H7 }\end{array}$ \\
\hline $\begin{array}{l}\text { Attitude } \\
\text { Listener } \\
\text { Loyalty }\end{array}$ & $->$ & 0.450 & 6.701 & 0.000 & $\begin{array}{l}\text { Significant } \\
\text { H8 }\end{array}$ \\
\hline $\begin{array}{l}\text { Subjective } \\
\text { Norm } \\
\text { Attitude }\end{array}$ & $->$ & 0.123 & 2.024 & 0.043 & $\begin{array}{l}\text { Significant } \\
\text { H9 }\end{array}$ \\
\hline $\begin{array}{l}\text { Subjective } \\
\text { Norm } \\
\text { Listener } \\
\text { Loyalty }\end{array}$ & $->$ & 0.124 & 1.782 & 0.075 & $\begin{array}{l}\text { Not } \\
\text { significant } \\
\text { H10 }\end{array}$ \\
\hline $\begin{array}{l}\text { Subjective } \\
\text { Norm } \\
\text { Perceived } \\
\text { Control }\end{array}$ & $->$ & 0.214 & 2.519 & 0.012 & $\begin{array}{l}\text { Significant } \\
\text { H11 }\end{array}$ \\
\hline $\begin{array}{l}\text { Perceived } \\
\text { Control } \\
\text { Attitude }\end{array}$ & $->$ & 0.526 & 8.964 & 0.000 & $\begin{array}{l}\text { Significant } \\
\text { H12 }\end{array}$ \\
\hline $\begin{array}{l}\text { Perceived } \\
\text { Control } \\
\text { Listener } \\
\text { Loyalty }\end{array}$ & $->$ & 0.154 & 2.213 & 0.027 & $\begin{array}{l}\text { Significant } \\
\text { H13 }\end{array}$ \\
\hline \multicolumn{6}{|c|}{ Indirect Effect } \\
\hline $\begin{array}{l}\text { Exposure } \\
\text { Frequency } \\
\text { Attitude } \\
\text { Listener } \\
\text { Loyalty }\end{array}$ & $->$ & 0.056 & 2.011 & 0.044 & Significant \\
\hline Exposure & & 0.027 & 1.549 & 0.122 & Not \\
\hline
\end{tabular}
observed indicators. In SEM, a variable is either exogenous or endogenous. An exogenous variable has path arrows pointing outwards and none leading to it. Meanwhile, an endogenous variable has at least one path leading to it and represents the effects of other variable(s).
Table 5. Path coefficients (Mean, STDEV, T-Values) 


\begin{tabular}{|c|c|c|c|c|c|}
\hline $\begin{array}{l}\text { Frequency } \\
\text { Subjective } \\
\text { Norm } \\
\text { Listener } \\
\text { Loyalty }\end{array}$ & $\begin{array}{l}-> \\
->\end{array}$ & & & & significant \\
\hline $\begin{array}{l}\text { Exposure } \\
\text { Frequency } \\
\text { Perceived } \\
\text { Control } \\
\text { Listener } \\
\text { Loyalty }\end{array}$ & -> & 0.017 & 1.171 & 0.242 & $\begin{array}{l}\text { Not } \\
\text { significant }\end{array}$ \\
\hline \multicolumn{6}{|c|}{ Total Indirect Effect } \\
\hline $\begin{array}{l}\text { Exposure } \\
\text { Frequency } \\
\text { Listener } \\
\text { Loyalty }\end{array}$ & $\rightarrow$ & 0.156 & 3.717 & 0.000 & Significant \\
\hline $\begin{array}{l}\text { Subjective } \\
\text { Norm } \\
\text { Listener } \\
\text { Loyalty }\end{array}$ & $->$ & 0.139 & 2.977 & 0.003 & Significant \\
\hline $\begin{array}{l}\text { Perceived } \\
\text { Control } \\
\text { Listener } \\
\text { Loyalty }\end{array}$ & $->$ & 0.236 & 5.346 & 0.000 & Significant \\
\hline
\end{tabular}

Source: processed data (2021)

Thus, the SEM Path Diagram will be:

Hypothesis 1 : AOD exposure frequency is positively related to individual attitude toward AOD loyalty

From the table ***4.20 (Path coefficients (Mean, STDEV, T-Values) it is found that the T-statistical value $(2.037)>1.96$ and $\mathrm{P}-$ Value $(0.042)<0.05$, and the original sample value is 0.124 (positive sign) From these results, the hypothesis which states that the AOD exposure frequency is positively related to individual attitude is received, the higher the AOD exposure frequency, the higher the individual attitude.

Meanwhile, to determine the indirect effect (AOD exposure frequency is positively related to individual attitude toward AOD loyalty) the T-statistical value $(2.011)>1.96$ and P-Value $(0.044)<0.05$, and the original sample value of 0.056 (positive sign). From these results, it can be stated that there is an indirect effect of AOD exposure frequency is positively related to individual attitude toward AOD loyalty.

This is an important finding, in contrary of Mou which the communication frequency do not have direct effect toward attitude except via subjective norm, in this case the audio exposure has determinant effect for the listener's attitude [3]. But this one is making more sense, it is like a listening habit once, someone accustomed to specific background audio.
Respondents also stated that they were aware of the audio exposure they encountered, with an average of 4.8 hours. And the average minute consuming Podcast or Video Cast is 45 minutes per day on average or about $15.6 \%$ using the "share of ear" method.

Hypothesis 2: AOD exposure frequency is positively related to subjective norm toward AOD loyalty.

From the table ***4.20 (Path coefficients (Mean, STDEV, T-Values) it is found that the T-statistical value $(3.537)>1.96$ and $\mathrm{P}-$ Value $(0.001)<0.05$, and the original sample value is 0.22 (signed from these results, the hypothesis states that the AOD exposure frequency is positively related to subjective norm is received. The higher the AOD exposure frequency, the higher the subjective norm.

Meanwhile, to determine the indirect effect (AOD exposure frequency is positively related to subjective norm toward AOD loyalty) the T-statistical value $(1.549)<1.96$ and P-Value $(0.122)>0.05$, and the original sample value of 0.027 (positive sign). From these results, it can be stated that there is no indirect effect of AOD exposure frequency related to subjective norm toward AOD loyalty.

This is corresponding to Mou finding that subjective norms is being dependent on the frequency of conversation, in this case is audio exposure [3]. From then on, the barrier between the usage of radio, as is using the radio frequency and on demand audiobased media, such as an example of podcasting, is narrowing. Added with the trend that most conventional media usage is in decreasing trend, the audio-based media is increasingly up[28].

Hypothesis 3: AOD exposure frequency will positively relaed to individual's AOD Loyalty

From the table $* * * 4.20$ (Path coefficients (Mean, STDEV, T-Values) it is found that the T-statistical value $(0.293)<1.96$ and $\mathrm{P}$-Value $(0.769)>0.05$, and the original sample value is 0.019 (positive sign) From these results, the hypothesis which states that AOD exposure frequency will be positively related to individual's AOD Loyalty is rejected. AOD exposure frequency has a positive but not significant effect on individual's AOD Loyalty.

This hypothesis is derived from Mou finding that communication frequency regarding podcast have positive affect toward the intention to listen and with addition of the way Edison Research data came from audio exposure frequency, the result is not proven in this test $[18,3]$. Hanyang Luo introduced different 
website type as moderating variable to explore website quality whether has different influence on user loyalty related to different website styles, this object can make up the gap that former research only chose one kind of website. In this paper also using the Content Density as the "Website Information Quality" variable to see how 'hedonism' content affecting user loyalty[29].

Hypothesis 4: AOD exposure frequency is positively related to individual perceived behavior control toward AOD loyalty

From the table ***4.20 (Path coefficients (Mean, STDEV, T-Values) it is found that the T-statistical value $(1.576)<1.96$ and $\mathrm{P}$-Value $(0.115)>0.05$, and the original sample value is 0.109 (positive sign) From these results, the hypothesis which states that AOD exposure frequency is positively related to individual perceived behavior control is rejected.

Meanwhile, to determine the indirect effect (AOD exposure frequency is positively related to individual perceived behavior control toward AOD loyalty), the T-statistical value $(1.171)<1.96$ and P-Value $(0.242)$ $>0.05$, and the original sample value of 0.017 (positive sign). From these results, it can be stated that there is no indirect effect of AOD exposure frequency is positively related to individual perceived behavior control toward AOD loyalty.

A number of experiments in this place received extensive media attention and also the usually promulgated findings are that individuals are terrible multitaskers, that folks are powerless to multitask, or even that multitasking actively damages concentration and cognition [12]. The assumption of assuming exposure frequency will affect the tools adoption is not proven, with the advancement of technology of recommendation service and great user interface and experience from tools toward millenials stating actually the other way around. Tools that bring the audio exposure [17,23].

Hipotesis 5: Attitude toward AOD is positively related to AOD-Loyalty

From the table ***4.20 (Path coefficients (Mean, STDEV, T-Values) it is found that the T-statistical value $(6.701)>1.96$ and $\mathrm{P}$-Value $(0.000)<0.05$, and the original sample value is 0.45 (signed From these results, the hypothesis which states that Attitude toward AOD is positively related to AOD-Loyalty is received. Attitude toward AOD has a positive and significant effect on AOD-Loyalty. The higher the
Attitude toward AOD, the higher the AOD-Loyalty. Attitude is always a determining factor toward behavior, this study same as Mou and Lyn, the direct and indirect affects toward behavior is through Attitude as on the driving variables [3]. Hanyang Luo whose research was based on the literature relevant to the connection between site quality and users' attitude or behavior, we adopt the technology acceptance model (TAM) and stimulus - organism - response (S$\mathrm{O}-\mathrm{R}$ ) principle to create a conceptual design, learning how the site quality impact user devotion through users' perceived commitment and value through hedonism value [24].

Hypothesis 6: Perceived subjective norm associated toward AOD is positively related to AOD loyalty attitude

From the table $* * * 4.20$ (Path coefficients (Mean, STDEV, T-Values) it is found that the T-statistical value $(2.024)>1.96$ and $\mathrm{P}-$ Value $(0.043)<0.05$, and the original sample value is 0.123 (positive sign) From these results, the hypothesis states that Perceived subjective norm associated toward AOD is positively related to AOD loyalty attitude is received. Perceived subjective norm has a positive and significant influence on AOD loyalty attitude. The higher Perceived subjective norm, the higher AOD loyalty attitude will be. Another conformation on the previous study of Mou, which social norm have direct confirmatory effect toward the attitude, such as peer pressure $[3,24]$. Mou stated Lee's study as "By the same token, a study focusing on the intention to play online games suggested that player attitude, perceived subjective norms, and perceived behavioral control, in addition to flow experience and perceived enjoyment, all had an influence on an individual's intention to continue playing these online games"[24].

Hypothesis 7: Perceived subjective norm associated with AOD use is positively related to individual's AOD loyalty

From the table $* * * 4.20$ (Path coefficients (Mean, STDEV, T-Values) it is found that the T-statistical value $(1.782)<1.96$ and $\mathrm{P}$-Value $(0.075)>0.05$, and the original sample value is 0.124 (positive sign) From these results, the hypothesis which states that Perceived subjective norm associated with AOD use is positively related to individual's AOD loyalty is rejected. Perceived subjective norm has a positive but insignificant effect on individual's AOD loyalty. The descriptive norm instead of injunctive norm as part of 
the subjective norm is shown the positive effect toward behavior, so this result is more relates to injunctive norms in Mou's Theory of Planned Behavior model [3]. The past decade indicates a sharp increase in investigation examining people's capacity to multitask. A fair level of that analysis is centered on a certain kind of multitasking named media multitasking[24].

Hypothesis 8: Perceived subjective norm associated toward AOD is positively related to AOD loyalty perceived control.

From the table ***4.20 (Path coefficients (Mean, STDEV, T-Values) it is found that the T-statistical value $(2.519)>1.96$ and $\mathrm{P}$-Value $(0.012)<0.05$, and the original sample value is 0.214 (positive sign) From these results, the hypothesis which states that Perceived subjective norm associated toward AOD is positively related to AOD loyalty perceived control is received. Perceived subjective norm has a positive and significant influence on AOD loyalty perceived control. The higher the Perceived subjective norm, the higher AOD loyalty perceived control. Social norm is driving force for tools recommendation and this one is correspond toward Mou finding in injunctive norm as well as the report from Westwood One on how listeners get their tips for podcast exploration $[3,19]$. Given these two components, the authors can certainly then define success by attaining some level of overall performance in the multitasking condition with respect to the control condition. To have the ability to evaluate results across studies and theoretical approaches, the studies selected for this analysis and reported here use any activity problem while the control condition.

Hypothesis 9: Perceived behavior control associated toward AOD is positively related to AOD loyalty attitude.

From the table ***4.20 (Path coefficients (Mean, STDEV, T-Values) it is found that the T-statistical value $(8.964)>1.96$ and $\mathrm{P}$-Value $(0.001)<0.05$, and the original sample value is 0.626 (positive sign) From these results, the hypothesis which states that the Perceived behavior control associated toward AOD is positively related to AOD loyalty attitude is received. The higher the Perceived behavior control, the higher the AOD loyalty attitude.This hypothesis confirming also previous study from Mou [3]. Nic Newman stating this changing behavior are for the advantages for audio media due to all this trend in hearables equipment will improve the interruption of radio schedules and activate more on demand audio usage[19].

Hypothesis 10 : Perceived Behavior Control over AOD is positively related to AOD Loyalty

From the table ***4.20 (Path coefficients (Mean, STDEV, T-Values) it is found that the T-statistical value $(2.213)>1.96$ and $\mathrm{P}$-Value $(0.027)<0.05$, and the original sample value is 0.154 (positive sign) From these results, the hypothesis which states that Perceived Behavior Control over AOD is positively related to AOD Loyalty is received. Perceived Behavior Control has a positive and significant influence on AOD Loyalty. The higher the Perceived Behavior Control, the higher the AOD Loyalty. In contrary from Mou's finding, perceived behavior control in this variable is looking the recommendation service for helping the users find what they want. With the advancement of recommendation technology, this might change toward the behavior of users by getting better recommendation at the time of the research $[3,17]$. Many study is either ignoring the variety of streaming audio in general and treated as digital channel or becoming too niche in studying one sub channel of AOD and ignoring the others [30]. Geographical location also affecting the availability of variation of AOD, for example, satellite audio stream play a big roles for coast to coast driving commuter in North America.

\section{Conclusion}

Based on the analysis and discussion above, it can be concluded that the frequency of AOD exposure is positively related to the individual's attitude of being accepted, that there is an indirect effect that the frequency of AOD exposure is positively related to the individual's attitude towards AOD loyalty. While the frequency of exposure to AOD is positively related to accepted subjective norms. From these results it can be stated that there is no indirect effect of the frequency of AOD exposure related to subjective norms on AOD loyalty. While the frequency of AOD exposure is positively related to individual AOD Loyalty is rejected, the frequency of AOD exposure has a positive but not significant effect on individual AOD Loyalty. From these results, the hypothesis which states that the frequency of AOD exposure is positively related to individual perceived behavioral control is rejected. From these results it 
can be stated that there is no indirect effect of the frequency of AOD exposure that is positively related to individual perceived behavioral control on AOD loyalty. While the attitude towards AOD is positively related to AOD-Loyalty is accepted. Attitude towards AOD has a positive and significant effect on AODLoyalty. From these results, the hypothesis states that Perceived subjective norm is positively related to the attitude of loyalty AOD is accepted. Perceived subjective norm has a positive and significant effect on AOD loyalty attitudes. From these results the hypothesis which states that the perception of subjective norms related to the use of AOD is positively related to individual AOD loyalty is rejected. Perceived subjective norms have a positive but not significant effect on individual AOD loyalty. Perceived subjective norm is positively related to AOD loyalty perceived control is accepted. Perceived subjective norm has a positive and significant effect on AOD loyalty perceived control. From these results obtained a hypothesis which states that Perceived behavior control related to AOD is positively related to AOD loyalty attitudes. From these results obtained a hypothesis which states that Perceived Behavior Control over AOD is positively related to AOD Loyalty. Perceived Behavior Control has a positive and significant effect on AOD Loyalty.

\subsection{Theoretical Implication}

The perceived behavior control is a perception of user experience toward the control factors within experience, in this case, this study might give some exploratory study toward the tools adoption, especially the research recommendation service satisfaction, user interface, and user experience.

The recommendation service is one of the strong points on tools adoption. It has been known in predicting what people want to see, the same algorithm that start the functionality from ads targeting, but now more toward the content recommendation also to increase the time-spent of stickiness. The best system for multimedia content recommendation is YouTube, Netflix, Pandora, and Spotify, and it expanding to another platform as well.

Behind the deep learning capabilities powered with artificial intelligent, are an abundant of big data in term of variety and velocity of it for example YouTube current published algorithm include three parts:

- Scale: Many current recommendation algorithms shown to work nicely on problems that are small fail to run on the scale of YouTube. Extremely specialized distributed learning algorithms and cost-efficient serving methods are important for managing YouTube's significant pc user.

- Freshness: YouTube has an extremely powerful corpus with a lot of hours of video are uploaded per next. The recommendation product must be responsive adequate to model freshly uploaded content along with the newest actions taken by the computer user. Balancing brand new content with wellestablished videos can be known from an exploration/exploitation viewpoint.

- Noise: Historical pc user conduct on YouTube is inherently hard to predict because of sparsity and an assortment of unobservable outside factors. We rarely get the soil fact of consumer pleasure plus as an alternative unit loud implicit feedback signal.

According to Karen Hao[3] among the proposed update for YouTube algorithm, the scientists specifically focus on an issue they recognize as "implicit bias." It describes how recommendations themselves can impact operator behavior, making it difficult to decipher whether you clicked on a video and audio recording since you liked it or perhaps since it had been highly recommended. The impact is the fact that over time, the device is able to push users even further and further separate from the movies they want to watch or listen, and this is also explain even though YouTube is intentionally serving for video, but it is a popular knowledge, that people are mostly listening to the video while there eyes are watching the second screen and the algorithm to find that "implicit bias" will cover the audio channels also. Westwood One even reporting that many podcast users are listening and discovery through YouTube along with other podcast platform that they use.

This research also find that YouTube is the number two choice among Millennials in Jakarta Indonesia to explore and finding the audio-based content. With this content density metric approach, it will be easier for the recommendation service to suggest the right content based on the noise and multimedia tasking that the users are encounter. And this also correspond to this finding that tools adoption (perceived behavior control) has significant effect toward loyalty. 


\subsection{Managerial Implication}

This study confirms that tools adoption via tools adoption is the important aspect that affecting listeners perception toward the content or its loyalty to the content itself. We had learned how YouTube create a rabbit-hole for its users, and YouTube also becoming the major player in audio-based media indirectly due to its highly contagious recommendation system. Secondly, the peer pressure through social norm, is also affecting attitude and tools adoption, in this case big players are having both capabilities: managing big users based to create social norm effects, while they also sharpening the big data usage to improve the personalization to the users.

Now, as content owners who do not have those capabilities, the best way is to adapt and distribute the content to a larger hub. We can learn from the podcast industry that when IHeartMedia use its platform to be exclusive platform for its exclusive contents, but finally it changes the strategy to expanding its content through other application tools also, naming Spotify, Apple Podcast, Pocket Cast (own research). For this reason, the strategy of content distribution to popular hub or content aggregation platform is one of the keys to get more audience.

Podcast has been popular in United States because of the popularity of Podcast, audio and mobility is corelating tightly, and with audio content that can have the time-shift ability, when Apple put the podcast as part of the iTunes software that can be synchronized to the iPod (which inspiring the name of Podcast), the popularity of podcast becoming more mainstream. In Indonesia, podcast became popular just the same time Spotify became popular in Indonesia, within short time Podcast becoming the household talks in many radio lovers in Indonesia.

With the same analogy of chicken or egg that comes first, we can see that between exposure frequency or tools adoption, the research shows that tools adoption has direct effect through loyalty of users, while exposure frequency has indirect effect to loyalty via social norm then tools adoption. In this case tools adoption is very important factors that hooked listeners to content loyalty.

This research also shows that there is peer pressured toward the using of certain applications, and the tools adoption also will influence the attitude which then will lead to loyalty to listen more on involved in advocating the channels that they listen. And since tools adoption is also influencing the attitude of users, through user experience, this will have double advantage when the media take advantage of available tools effectively to expand their media reach.

\section{References:}

[1] Markman, Kris M., and Caroline E. Sawyer. "Why pod? Further explorations of the motivations for independent podcasting." Journal of Radio \& Audio Media 21.1, 2014,20-35.

[2] Markman, Kris M. "Considerations-Reflections and future research. Everything old is new again: podcasting as radio's revival." Journal of Radio \& Audio Media 22.2, 2015, 240-243.

[3] Mou, Yi, and Carolyn A. Lin. "Exploring podcast adoption intention via perceived social norms, interpersonal communication, and theory of planned behavior." Journal of Broadcasting \& Electronic Media 59.3,2015, 475-493.

[4] Bressan, Federica. "A framework for the description of age-related symptoms in audio media: Definition and implementation." Studies in Conservation 65.4, 2020,189-199.

[5] Cebeci, Zeynel, and Mehmet Tekdal. "Using podcasts as audio learning objects." Interdisciplinary Journal of E-Learning and Learning Objects 2.1,2006,47-57.

[6] Ractham, Peter, and Xuesong Zhang. "Podcasting in academia: A new knowledge management paradigm within academic settings." Proceedings of the 2006 ACM SIGMIS CPR conference on computer personnel research: Forty four years of computer personnel research: achievements, challenges \& the future. 2006.

[7] Cook, Ian M. "Critique of podcasting as an anthropological method." Ethnography, 2020,1466138120967039.

[8] Llinares, Dario, Neil Fox, and Richard Berry. "Introduction: Podcasting and podcastsParameters of a new aural culture." Podcasting. Palgrave Macmillan, Cham, 2018,1-13.

[9] Llinares, Dario, Neil Fox, and Richard Berry, eds. Podcasting: New aural cultures and digital media. Springer, 2018.

[10] Ajzen, Icek. "Attitude personality and behaviour 2nd." New York: Open University Pres (2005).

[11] Knabe, Ann Peru. Applying Ajzen's theory of planned behavior to a study of online course adoption in public relations education. Marquette University, 2012. 
[12] Ndubisi, Nelson. "Factors of online learning adoption: A comparative juxtaposition of the theory of planned behaviour and the technology acceptance model." International Journal on Elearning 5.4, 2006,571-591.

[13] Yu, Tai- Kuei, and Tai- Yi Yu. "Modelling the factors that affect individuals' utilisation of online learning systems: An empirical study combining the task technology fit model with the theory of planned behaviour." British Journal of Educational Technology 41.6 (2010): 1003-1017.

[14] Xigen, L. I., and Li Zeng. "Technology Attributes, Perceived Value and Quality of Information, and Social Utility as Predictors of Podcast Adoption and Use." 59th Annual Conference of the International Communication Association (ICA). 2009.

[15] Moss, Nathan D., Erin L. O'Connor, and Katherine M. White. "Psychosocial predictors of the use of enhanced podcasting in student learning." Computers in Human Behavior 26.3, 2010,302-309.

[16] Havlena, William, Robert Cardarelli, and Michelle De Montigny. "Quantifying the isolated and synergistic effects of exposure frequency for $\mathrm{TV}$, print, and internet advertising." Journal of Advertising Research 47.3, 2007, 215-221.

[17] Hao, Karen. "YouTube is experimenting with ways to make its algorithm even more addictive." MIT Technology Review, September 27, 2019,2019.

[18] Edison Research. THE PODCAST CONSUMER 2017 \#PodCon17. Retrieved from http://www.edisonresearch.com/wpcontent/uploads/2017/04/Podcast-Consumer2017.pdf

[19] Westwood One. Westwood One's Podcast Download Fall 2020 Report. In WestWood One. Retrieved from https://www.westwoodone.com/wpcontent/uploads/2020/09/Westwood-OnesPodcast-Download-Fall-2020-Report.pdf

[20] Raykov, Tenko. "Estimation of composite reliability for congeneric measures." Applied Psychological Measurement 21.2, 1997,173-184.

[21] Hair Jr, Joe F., et al. "PLS-SEM or CB-SEM: updated guidelines on which method to use." International Journal of Multivariate Data Analysis 1.2, 2017,107-123.

[22] Ardi, Noper. "Structural Equation ModellingPartial Least Square to Determine the Correlation of Factors Affecting Poverty in Indonesian Provinces." IOP Conference Series: Materials Science and Engineering. Vol. 846. No. 1. IOP Publishing, 2020.

[23] Punnett, Ian. "Digital is the future-and the now: EmPosium on digital platform listening trends." (2016): 4-19.

[24] Christian, J., A. Rivis, and P. Sheeran. "Descriptive norms as an additional predictor in the theory of planned behavior: A metaanalysis." Planned Behavior 22.3, 2018,43-62.

[25] Carey, John. "Audience measurement of digital TV." International journal of digital television 7.1, 2016,119-132.

[26] Boling, Kelli S., and Kevin Hull. "Undisclosed information-Serial is My Favorite Murder: Examining motivations in the true crime podcast audience." Journal of Radio \& Audio Media 25, no. 1 (2018): 92-108.

[27] Bhatt, Swati. The attention deficit: unintended consequences of digital connectivity. Springer Nature, 2019.

[28] Lee, Mark JW, Charlynn Miller, and Leon Newnham. "Podcasting syndication services and university students: Why don't they subscribe?." The Internet and Higher Education 12, no. 1 (2009): 53-59.

[29] Luo, Hanyang, Xinwei Han, and Yanan Yu. "The impact of website quality on user loyalty through perceived value and commitment." In 2016 13th International Conference on Service Systems and Service Management (ICSSSM), pp. 1-5. IEEE, 2016.

[30] Bonini, Tiziano. "Doing radio in the age of Facebook." Radio Journal: International Studies in Broadcast \& Audio Media 12, no. 1-2 (2014): 73-87.

\section{Contribution of Individual Authors to the Creation of a Scientific Article (Ghostwriting Policy)}

Jerry S Justianto is the main author of this article and also plays a role in analyzing the statistical data generated in this study.

$M$ Arief is an expert in the field of research management, he is very helpful in providing input and input in this research so that it can produce quality research.

Indah Susilowati is an expert in the field of economics and research management, she is also an expert in the field of economics so she is very 
instrumental in providing input on the use of theories in this research in order to produce quality research.

Muhamad Aras is an expert in marketing communications, online behavior and social communication, he plays a role in providing input and input in this research so that it can produce quality research.

Sources of Funding for Research Presented in a Scientific Article or Scientific Article Itself

All funding in this study came from private funding.

Creative Commons Attribution License 4.0 (Attribution 4.0 International, CC BY 4.0)

This article is published under the terms of the Creative Commons Attribution License 4.0

https://creativecommons.org/licenses/by/4.0/deed.en $\underline{\mathrm{US}}$ 